\title{
Issues in the development and use of food composition databases
}

\author{
Prapasri Puwastien* \\ Institute of Nutrition, Mahidol University at Salaya, Phuttamonthon 4, Nakorn Pathom 73170, Thailand
}

\begin{abstract}
Objectives: To share experience on the development of national and regional food composition tables (FCTs) and the issues and problems involved.

Design: Food composition data analysed at national and regional levels were compiled. Systematic development of FCTs detailing specific criteria and characteristics following the INFOODS and ASEANFOODS guidelines was conducted.

Setting: The national FCT was developed using the Thai FCT as a study model. For the regional level, the Association of South East Asian Nations (ASEAN) FCT was developed.

Subjects: About 3000 analysed datasets of about 1000 food items on proximate composition, minerals, vitamins and other available components from various sources in Thailand and about 4500 analysed datasets of 1700 food items on the same components from various countries in ASEAN were compiled. The national and regional FCTs were then developed systematically.

Results: The developed Thai FCT contains 24 nutrients of 1055 food items and the ASEAN FCT contains 21 nutrients of about 1740 food items. Issues and problems regarding the development and use of national and regional food composition data are listed.

Conclusion: Food composition databases have become increasingly important in the international health arena. Systematic compilation of the data is necessary and the use of INFOODS tag names is strongly recommended. This is to indicate the methods of nutrient analysis and calculation, and to facilitate international and regional data interchange. Users are also recommended to read the Explanatory Notes and Information to the Users. Collaboration among data generators, users and compilers at national and regional levels, as well as support from international organisations, is essential.
\end{abstract}

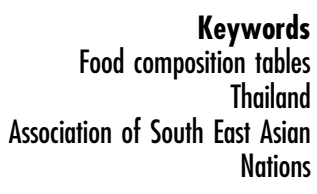

Sufficient consumption of quality foods provides adequate and balanced amounts of nutrients for good nutrition and health. This leads to enhanced quality of life and increases the potential of human resources, which is vital for national socio-economic development. However, owing to rapid economic growth and technological advances in most countries of the Association of South East Asian Nations (ASEAN), their populations have tended gradually to change their lifestyles and food habits, resulting in less physical exercise and excessive, unbalanced dietary intake. With the increasing trend in nutrition problems, especially overnutrition, there has been growth in studies on the relationship between diet and disease, nutritional assessments of specific populations, the need for nutritional intervention, and other nutrition-related activities. At the same time, increasing demand for high-quality food products and global expansion of the food industry and trade have placed emphasis on food research and development, food formulation and fortification, and nutrition labelling requirements. Food composition databases from various countries become more and more important for local and international use. This paper addresses issues regarding the systematic development and use of national and regional food composition data, using the food composition tables (FCTs) of Thailand and ASEAN as study models.

\section{Food composition databases: national and regional}

In 1983, the United Nations University (UNU) established the International Network of Food Data System (INFOODS) to improve the quantity, quality and accessibility of food composition data. Subsequently, various regional networks have been formed to encourage these activities, and to facilitate collaboration and the interchange of information and knowledge between countries and regions.

The ASEAN Network of Food Data System (ASEANFOODS) was established in 1986 with member countries comprising Indonesia, Malaysia, the Philippines, Singapore, Thailand and Brunei Darussalam. Vietnam joined the network in 1996. In order to co-ordinate the activities of the member countries, the Institute of Nutrition at Mahidol 
University (INMU) was appointed as the Network's Regional Centre in 1986, and as the INFOODS Regional Database Centre in 1991.

\section{Status of national food composition databases in ASEAN}

All of the country members of ASEAN have their own FCT except Brunei Darussalam. Table 1 shows the characteristics of the FCTs in ASEAN countries. The English language is used as standard in all FCTs except that of Indonesia, where English is provided in the index only, and that of Vietnam, where the explanatory notes are in Vietnamese. Most of the data were self-generated, except for Vietnam. Malaysia, Singapore and Thailand each have developed nutrient computation software to facilitate data users. In addition, Malaysia and Singapore have electronic data products, such as a web site, to assist in public education.

All national FCTs present food composition data as the amount of nutrient per $100 \mathrm{~g}$ of edible portion. In the case of Malaysia, the nutrient amount per household serving is also included. The FCTs of Indonesia, Malaysia and Vietnam contain proximate composition data with crude fibre values, whereas those of the Philippines, Singapore and Thailand show dietary fibre data ${ }^{1-6}$. Users must note that the carbohydrate values in FCTs from each country were obtained by using three different methods of calculation, which result in different values of total energy content. The value of carbohydrate derived from the sum of starch and total sugars in the Singapore FCT seems to be the most appropriate one. The most common vitamin and mineral data are available in all tables. In addition, some of the FCTs contain other components with health implications, such as fatty acids, cholesterol and sugars.

\section{Systematic development of national food composition databases}

Food composition data in each country are usually available as published and unpublished analytical data and all, except for Brunei Darussalam, have their previous version of FCT. Hence, the development of FCTs is currently a process mostly to compile new data from published and unpublished sources in order to update the previous version. In addition, some countries may change the format and content to comply with national and international users' requirements, or to replace/delete the old data.

Only recently, the first English version of the Thai food composition database was developed systematically. This development was based on the guidelines set by Greenfield and Southgate ${ }^{7}$, INFOODS ${ }^{8}$ and the ASEANFOODS Technical Committee ${ }^{9}$. Its development is therefore presented as the study model.

\section{Thailand experience: a study model}

Based on the above guidelines, an ad boc technical committee comprised of food analysts, data programmers, data compilers and data users was formed at the INMU. The group discussed, proposed and agreed upon a set of criteria for the development of the Thai food composition database and criteria for the evaluation of analytical data. The activities were then carried out step-by-step as follows.

\section{Step 1: Compilation of published and unpublished data} and systematic development of archival files

A survey of unpublished and published analytical food composition data from 1977 onwards was carried out. Wherever possible, photocopies of published papers were collected. Available data and detailed information from various sources were compiled, including the printed FCT published by the Ministry of Public Health ${ }^{10}$, published papers in various journals, published data in university theses and reports from scientific proceedings, as well as unpublished laboratory data from the INMU and other government institutions. They were selected according to the following criteria:

1. the data must be original and analytical data;

2. sampling, sample preparation, analytical methods and the number of samples analysed should be documented;

3. the origin of the analytical data can be traced back; and

4. minimum data available include proximate composition or minerals or vitamins and moisture content.

\section{Step 2: Systematic development of archival files}

The data were reviewed and adjusted, as necessary, in order to have the same units of expression with each nutrient measured as the amount per $100 \mathrm{~g}$ of food. About 3000 datasets of about 1000 food items were then installed into a computerised system as spreadsheet data files according to a format agreed upon previously ${ }^{9}$; Microsoft Excel was selected as the compilation system for development of the archival files for the food composition data. Wherever possible, sources and details of the data were attached. Examples of the details are the number of samples analysed, sampling and sample preparation, laboratory number, analytical methods, food ingredients and brand name.

The identity of each food item - Thai name, common name and scientific name - was checked carefully by reference to documents from the Ministry of Agriculture and Cooperatives and other reference sources, usually with an illustration ${ }^{11-20}$. Food items in the archival files were categorised, in accordance with the ASEANFOODS guideline?, into 16 food groups. The assigned food codes were then presented, as shown in Table 2 . The nutrients in the database were identified by INFOODS tag names ${ }^{21,22}$, as shown in Table 3, together with the criteria for 


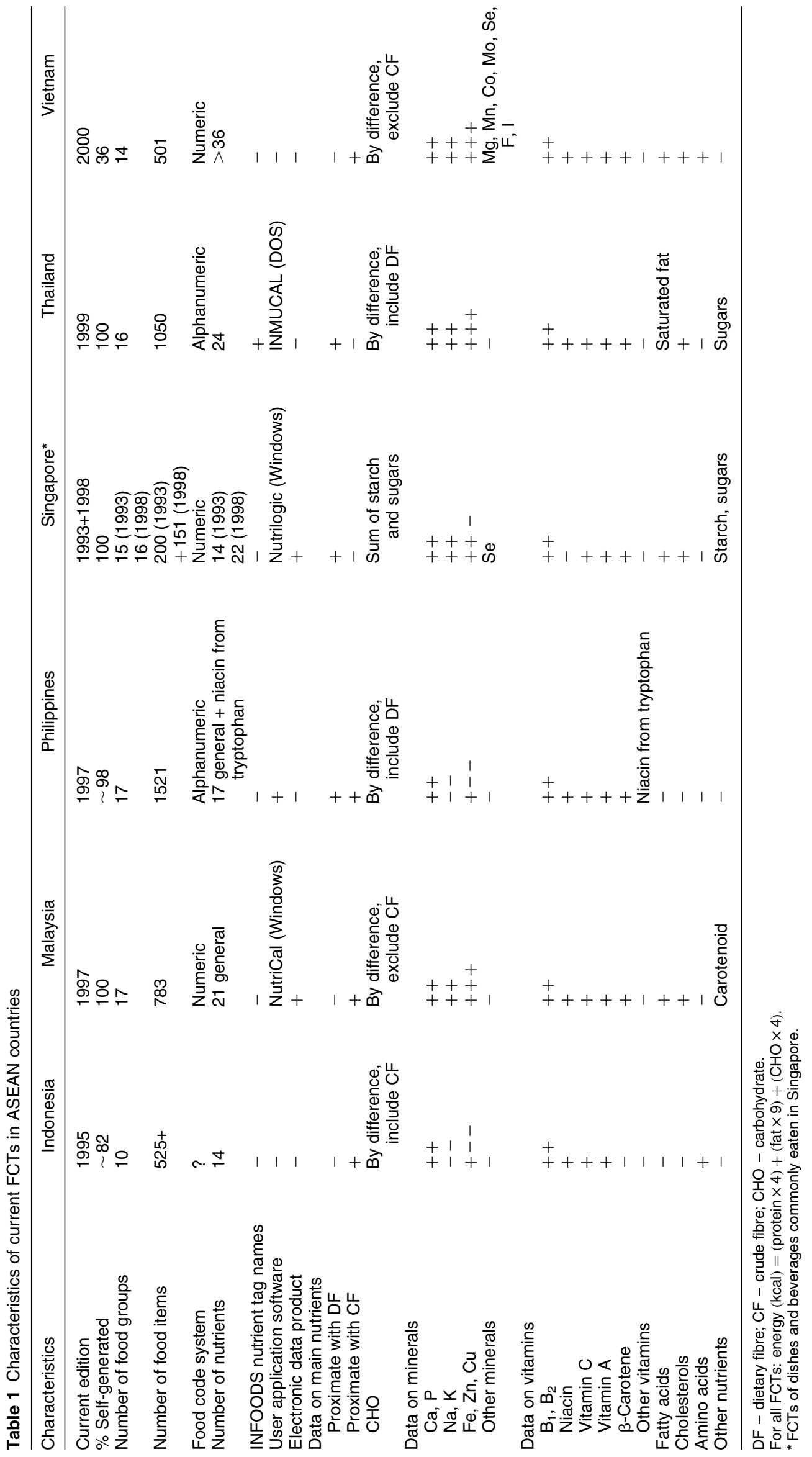


Table 2 Food groups and food codes

\begin{tabular}{rlc}
\hline & \multicolumn{1}{c}{ Food group } & Food code \\
\hline 1 & Cereals and products & $\mathrm{A}$ \\
2 & Starchy roots, tubers and products & $\mathrm{B}$ \\
3 & Legumes, nuts, seeds and products & $\mathrm{C}$ \\
4 & Vegetables and products & $\mathrm{D}$ \\
5 & Fruits and products & $\mathrm{E}$ \\
6 & Meat, other animal flesh and products & $\mathrm{F}$ \\
7 & Finfish, shellfish, other aquatic animals and & $\mathrm{G}$ \\
& products & $\mathrm{H}$ \\
8 & Eggs and products & $\mathrm{J}$ \\
9 & Milk and products & $\mathrm{K}$ \\
10 & Fats, oils and products & $\mathrm{M}$ \\
11 & Sugars, syrup and confectioneries & $\mathrm{N}$ \\
12 & Condiments and spices & $\mathrm{Q}$ \\
13 & Beverages, non-alcoholic & $\mathrm{S}$ \\
14 & Fast foods: franchise foods & $\mathrm{T}$ \\
15 & Mixed food dishes: local & $\mathrm{U}$ \\
16 & Miscellaneous & \\
\hline
\end{tabular}

The ASEAN FCT contains group 'P', 'Beverages, alcoholic'. Food codes of the other food groups in the ASEAN FCT are the same as those shown in this table.

acceptance of the data based on analytical methodologies, units of expression and the number of decimal points for each nutrient.

\section{Step 3: Development of the reference database ${ }^{7}$}

Data for the same food item in each food group of the archival files were arranged and listed together to form a pool of the total available data. A general check for the names and validity of the same set of data was repeated using descriptors and the moisture content as a guideline. Sets of data were then ready to be scrutinised to obtain a single set of nutrient information for each food item.

\section{Step 4: Development of the user database 7}

Scrutiny and assessment of each nutrient in each pooled dataset in the reference database were carried out using robust statistics ${ }^{23}$. With consideration of each food item, recalculation of nutrients with extreme value of moisture content was carried out based on the average of accepted value of moisture. The median and the normalised interquartile range (NIQR) were then calculated for each nutrient using the Excel program. Extreme values were identified by use of the $Z$-score, based on the median and the NIQR. Data with $Z$-scores outside the range of \pm 3 were not accepted. The mean and standard deviation values of the accepted dataset were then calculated and the mean value was used as the final value for each nutrient of the food item. Carbohydrate 'by difference' and the total energy value of each food item in the final set of user data files were then calculated.

All datasets of foods in the same food group were then arranged alphabetically according to Thai names. The sequence of food descriptors is from generic to specific, i.e. strain, part, process, maturity and grade. The alphanumeric system was applied for food coding. The alphabet character (Table 2) indicates the major food

Table 3 Nutrients, criteria of acceptance, INFOODS tag names and number of decimal places

\begin{tabular}{|c|c|c|c|c|}
\hline & $\begin{array}{l}\text { Nutrient } \\
\text { and units }\end{array}$ & $\begin{array}{c}\text { Criteria } \\
\text { of acceptance }\end{array}$ & $\begin{array}{l}\text { INFOODS } \\
\text { tag names }\end{array}$ & $\begin{array}{c}\text { Number } \\
\text { of decimal } \\
\text { places }\end{array}$ \\
\hline 1 & Moisture, g & All methods & WATER & 1 \\
\hline 2 & Protein, $\mathrm{g}$ & Total $\mathrm{N} \times$ converting factor & PROCNT & 1 \\
\hline 3 & Fat, $g$ & All methods, with acid digestion & FAT & 1 \\
\hline 4 & Dietary fibre, $g$ & Enzymatic gravimetric method & FIBTG & 1 \\
\hline 5 & Total available $\mathrm{CHO}, \mathrm{g}$ (include FIBTG) & $\begin{array}{l}\text { Calculated by difference: } 100 \mathrm{~g} \\
- \text { (total } \mathrm{g} \text { of water }+ \text { protein }+ \text { fat }+ \text { ash) }\end{array}$ & CHOCDF & 1 \\
\hline 6 & Ash, $\mathrm{g}$ & All methods & ASH & 1 \\
\hline 7 & Energy, kcal & $\begin{array}{l}\text { Calculated by }(4 \times \mathrm{g} \text { protein })+(9 \times \mathrm{g} \text { fat }) \\
+(4 \times \mathrm{g} \text { total } \mathrm{CHO})\end{array}$ & ENERC & None \\
\hline 8 & Calcium, mg & All methods & $\mathrm{CA}$ & None \\
\hline 9 & Phosphorus, mg & All methods & $\mathrm{P}$ & None \\
\hline 10 & Iron, mg & All methods & FE & 1 \\
\hline 11 & Sodium, mg & All methods & NA & None \\
\hline 12 & Potassium, mg & All methods & $\mathrm{K}$ & None \\
\hline 13 & Copper, mg & All methods & $\mathrm{CU}$ & 2 \\
\hline 14 & Zinc, $\mathrm{mg}$ & All methods & ZN & 1 \\
\hline 15 & Vitamin $\mathrm{B}_{1}, \mathrm{mg}$ & All methods & THIA & 2 \\
\hline 16 & Vitamin $B_{2}, \mathrm{mg}$ & All methods & RIBF & 2 \\
\hline 17 & Niacin, mg & All methods & NIA & 1 \\
\hline 18 & Vitamin C, mg & All methods & VITC & None \\
\hline 19 & Vitamin A (retinol), $\mu \mathrm{g}$ & All methods & RETOL & None \\
\hline 20 & $\beta$-Carotene, $\mu \mathrm{g}$ & All methods & CARTB & None \\
\hline 21 & Total vitamin A (retinol equivalent, RE), $\mu \mathrm{g} R E$ & All methods & VITA & None \\
\hline 22 & Total saturated fatty acids, $g$ & All methods & FASAT & 1 \\
\hline 23 & Cholesterol, mg & Gas-liquid chromatography & CHOLE & None \\
\hline 24 & Sugars, total, g & $\begin{array}{l}\text { Sum of free monosaccharides and } \\
\text { disaccharides }\end{array}$ & SUGAR & 1 \\
\hline
\end{tabular}

$\mathrm{CHO}$ - carbohydrate. 
group, while the numeric character represents the record number within the food group. This system assists users in searching through the required food composition data. It must be noted that once the food codes were assigned, they remained unchanged. The final user data files were then constructed. Missing values were left blank, without entries of any borrowed or calculated or estimated data. An index of food items in each food group was arranged alphabetically by the common English names with descriptors and with their assigned food codes, and then followed by scientific names, Thai names, source of data and the page number. This makes the system more user-friendly, especially for international users.

\section{Step 5: Camera-ready Thai food composition tables}

The final step was publishing the Thai Food Composition Tables $^{5}$. This was prepared as camera-ready FCTs. They include data for 16 food groups, listing 21 nutrients (proximate composition, minerals and vitamins) for 1055 food items. Data on moisture, total fat, saturated fat and sugar contents of 280 food items are presented separately in additional tables. It is expected that future food and nutrition research on nutrition assessment and other related aspects will be based on the same national food composition database, which will facilitate the possibilities for comparative studies.

\section{Systematic development of a regional food composition database}

On a regional basis, the Food and Agriculture Organization (FAO) joined UNU in 1994 to promote the activities of INFOODS and shares the task of completing global food composition data activities in the developing world. Thus, the activity of ASEANFOODS in developing a regional food composition database was reactivated.

Although national FCTs have been developed in most ASEAN countries, incomplete information surrounding nutrient data and certain common food items is a persisting problem facing users. The problem has been relieved by borrowing the data from national databases outside the region or from related foods. The availability of an ASEAN food composition database to obtain, retrieve, compare and exchange food composition data among ASEAN countries will help fulfil the data needs of ASEANFOODS member countries and others in the nearby regions where food composition data are lacking or not completely available. In addition, the regional food composition database serves multiple purposes, including the facilitation of intra-regional trade, collaborations in research projects, agricultural policy development, and public health programmes and policies.

\section{The first ASEAN food composition database}

In order to establish the ASEAN food composition database, a special technical committee was formed. It comprised technical co-ordinators from Malaysia (Dr Tee E Siong), the Philippines (Dr Aida Aguinaldo) and Thailand (Dr Prapasri Puwastien), and one expert from INFOODS (Dr Barbara Burlingame). Some guidelines for development of the ASEAN database were prepared ${ }^{9}$. A plan for a workshop entitled 'Creation of the first ASEAN Food Composition Database' was submitted to and approved by the Japan International Cooperation Agency (JICA). This workshop was crucial, since its implementation was the first stage in the development of a regional food composition database. The activities of the workshop were divided into three phases as follows.

Pre-workshop activities: preparation of archival files of the ASEAN food composition database

The combined existing national food composition databases from each country, which overall included a total of about 4500 food items, were reviewed and harmonised in terms of food group classification (altogether 17 food groups, similar to those in the Thai FCT, plus one extra group, 'P' of 'Beverages, alcoholic') and in terms of format, units of expression and number of decimal places, each based on the guidelines developed by the ASEANFOODS Technical Committee? Specific alphanumeric food codes (Table 2) including a country $\operatorname{code}^{24}$ (Table 4) were assigned for each food item from each country. The analysed nutrients were identified by INFOODS tag names (Table 3). Compilation and installation of the prepared database from each country, designed as spreadsheets, were pre-processed into a compilation system. The workshop was then convened at the INMU, Thailand in March 1996.

\section{ASEANFOODS workshop activities: preparation of} reference data files of ASEAN food composition database Representatives from each ASEAN country actively involved in food composition data compilation were invited. Nineteen ASEAN delegates from Indonesia, Malaysia, the Philippines, Singapore, Thailand and Vietnam, and two experts supported by INFOODS, participated in the workshop. Decisions critical to harmonisation and standardisation of the data files were made, and the group discussed and agreed upon a specific set of criteria for evaluation of the national food

Table 4 Lists of countries/region and the ISO/IFRI codes

\begin{tabular}{lc}
\hline Region/country & ISO/IFRI code \\
\hline ASEANFOODS & AA \\
Indonesia & ID \\
Malaysia & MY \\
Philippines & PH \\
Singapore & SG \\
Thailand & TH \\
Vietnam & VN \\
\hline
\end{tabular}

IFRI - International Food Record Identifier. 
composition databases for inclusion into the ASEAN food composition database. The participants were then divided into three working groups, each consisting of a representative from each country. Each working group evaluated the assigned data files according to the agreedupon criteria on the following aspects.

1. Identity of the food items and the food code in each country's data files.

2. Selection of the relevant food items from the archival files of the national FCTs, based on the following criteria:

- at least two countries have data for the same food item;

- one-record food items will be considered only when they are common among the member countries and they will be identified by country code;

- each food item should contain data of proximate composition or minerals or vitamins and moisture; and

- country food codes of primary sources will be included in the database.

3. Evaluation of the identity and completeness of the nutrient data files.

4. Re-examination of each dataset from the different countries in the data files to ensure that the correct identity of the food items is used. This is done to form a pool of the total available data files (reference database). Moisture content and descriptors were used as guidelines. Documents from the Ministry of Agriculture and Cooperatives and other references were used, usually with an illustration ${ }^{11-20,25,26}$.

5. Creation of the 'STATUS' of each food record' for further processing; for example, as 'unique', 'excluded', 'combined' or 'merged'.

At the end of the workshop, an ASEAN reference database of 17 food groups was obtained. Most foods consisted of 16-25 different nutrients plus the energy values. The percentage of edible portion was also available in the Malaysian and Philippines FCTs. Data scrutiny, assessment and the development of the regional database were carried out as post-workshop activities.

Post-workshop activities: preparation of user data files of ASEAN food composition database

Following the workshop, the Philippines and Thailand spent two to three additional years to complete data scrutiny and to prepare their user databases. They were then re-submitted to the Regional Centre. The ASEAN reference databases were then reviewed, re-examined and processed according to the 'STATUS' given by the technical experts from INFOODS and ASEANFOODS Regional Centre. All data, including the pool of the same food items with the status of 'merged', were listed alphabetically according to the English food names. An alphanumeric system for the ASEAN food record identifiers was constructed with two characters, 'AA' for $\mathrm{ASEAN}^{24}$, followed by one letter for the food group and the number of food items (Table 2). Scrutiny and an assessment of extreme values for each nutrient for the pooled datasets in the reference database were carried out using robust statistics ${ }^{23}$, following the same approach as that of the Thai FCT. Due to the fact that variation in the nutrient composition of foods in a region could be wider than the variation within a given country, nutrients with $Z$-scores outside the range of \pm 5 were identified as extreme values. Mean and standard deviation values for the accepted dataset were then calculated and the mean value was used as the final value for each nutrient in the food item. The carbohydrate content and energy content of each food item were calculated. English and scientific names and food codes were finally examined and approved, and were arranged alphabetically according to English names. Alternative names of food in local languages (Bahasa Malaysia, Filipino, Thai and Vietnamese), wherever available, were listed in an additional column next to the English names. The final user data files of approximately 1740 food items were then constructed. A camera-ready version of the ASEAN Food Composition Tables was prepared and the tables were published in the year $2000^{27}$.

\section{Issues and limitations in the development of national and regional food composition databases}

In developing food composition databases, there are several issues that need to be considered. It is also necessary to recognise any limitations that occurred along the process and in using those data, since a variety of users would have different expectations and requirements. The following describes some of the key concerns.

- Ideally, all users require good-quality food composition data. The analytical data included in most FCTs are compiled from various sources. Publications in journals usually have well-documented methods of sampling, analysis and laboratory quality control, and other details regarding the samples. Unpublished reports and food tables may not provide all of the information needed. The data obtained from these sources cannot, therefore, fulfil fully the ideal requirements of food composition data. Systematic data scrutiny and assessment of extreme values of the compiled data were thus necessary before merging.

- Data quality assessment systems have been developed for particular nutrients by several researchers ${ }^{28}$. A quality index is given to each nutrient based on a set of criteria and a confidence code is then determined. This assessment is practical for one particular nutrient; however, there are no criteria for assigning a confidence code to the whole dataset of a food item. These criteria 
should be promoted on a wider basis to encourage generation of good-quality data.

- To identify extreme values, a robust $Z$-score based on the median and NIQR was applied. The criterion was set at two levels: a $Z$-score of \pm 3 at national level and a $Z$-score of \pm 5 at regional level. A wider range of accepted $Z$-score was applied for regional FCTs since the variation of nutrient levels in foods in a region is wider than the variation within a country.

- Nutrients from various national databases that frequently showed a difference in concentration are calcium, $\beta$-carotene and vitamin A. Different methods of analysis, apart from natural variation, should be the main reason for these discrepancies.

- Data on fatty acids, cholesterol and sugars are available for a limited number of food items in some national FCTs and have not yet been compiled or included in the ASEAN FCT. More data for these particular nutrients, which are related to current nutritional problems, are required.

- Missing data of nutrients is one of the common problems faced by users. According to several questionnaire surveys, all data users require that the food composition database be complete (i.e. have no missing values), so that the calculated nutrient contents in a diet or recipes are not underestimated. Several procedures for estimating missing nutrient values in food composition databases were proposed by Schakel et $a l^{29}$. The procedures should be carried out at one institute in order to obtain a uniform set of data. These values must be clearly identified in the database.

- For data traceability, the same food code should be used in the national and regional FCTs and must remain unchanged in the following versions.

- Determination of the identity of food items is the most important and difficult step in developing food composition databases, particularly at the regional level when a great number of foods in each country is considered. Organising an ASEANFOODS workshop was, therefore, a crucial step. It not only provided the opportunity for representatives of each ASEAN country to share their responsibility in developing the regional database, but it also allowed them to identify their own food items. However, references with food illustrations are still essential. At present, a few homepages with food illustrations, food names, scientific names and some food descriptions have been established by several organisations $^{13,20}$. Collaboration and support from UNU/INFOODS and FAO to each regional network could help in constructing a complete homepage of different foods throughout the world. Food groups that frequently showed difficulties in identification and nomenclature are listed in descending order as follows: legumes, vegetables, fish, fruits and mixed dishes.

\section{Tips for using food composition databases}

There are few important aspects concerning effective use of food composition databases as follows.

- Year of publication: users should note the year when the data were established. Progress in the development of analytical methods can affect nutrient data enormously. For example, crude fibre analysis vs. dietary fibre, cholesterol analysed by spectrophotometer vs. gas-liquid chromatography, vitamins analysed by microbiological assay or chemical methods vs. highperformance liquid chromatography - each differs with respect to the values obtained.

- Source of data: most of the complete food composition databases contain values from chemical analyses as well as non-analytical values derived from various procedures for estimation. Users should pay attention to the source of data indicated in the database. One good example is the carbohydrate value in the national databases of ASEAN countries, which was obtained from different procedures of calculation. This resulted not only in different levels of carbohydrate but also total energy (calculated from amounts of carbohydrate, protein and lipid). INFOODS tag names ${ }^{21,22}$ should be applied since they indicate how the nutrient data are derived, which methods of analysis are used, and which formula is used for the calculation. This practice will also facilitate international and regional data interchange.

- Presentation of analytical data: most food composition databases present nutritive values as $\mathrm{g}, \mathrm{mg}$ or $\mu \mathrm{g}$ of nutrient per $100 \mathrm{~g}$ of food. Some FCTs may use different units of expression such as kJ for energy, International Unit (IU) for vitamin A and vitamin E, niacin equivalents for niacin, etc., which must be checked carefully when different FCTs are used concurrently.

- Data users always request expression of data per serving or common household unit. In ASEAN, only the FCT of Malaysia contains both nutrient per $100 \mathrm{~g}$ and per common household unit, that of Singapore provides weight of cooked food per measure as purchased, and the Thai FCT provides a list of reference amounts customarily consumed per eating occasion. This request has been taken into consideration in future revision of the FCT.

- Explanatory notes and information to the users: this part of the FCT should be read carefully. It usually informs the users how the food composition data are obtained and established.

- Food items in a food group: an overview of food items included in each food group could aid in food searching. Each FCT may classify food items differently depending on their use in the country or region. For example, in the ASEAN FCT, fresh spices are included in 'spices and condiments' instead of 'vegetables'; melon 
seeds are presented in 'legumes, nut, seeds' whereas melons are presented in 'fruits and products'.

- Validity of data: data compilers have tried their best to compile the most reliable data; however, some errors in the figures are bound to occur. Users could check some suspect data with other FCTs. For main nutrients, including dietary fibre, the sum should be within $100 \pm 3 \mathrm{~g}$ per $100 \mathrm{~g}^{7}$; the carbohydrate value should be close to the sum of starch, sugars and dietary fibre; the sum of minerals should not exceed the ash value; and total fatty acids should not be more than the value of total lipid.

\section{Conclusion}

In conclusion, there are food composition databases available at both national and regional levels in the ASEAN region. Data for some food items and nutrients in each national FCT may be missing. They may contain, to some extent, borrowed data and out-of-date self-generated data. However, food composition databases provide basic information essential to food and nutrition activities. Locally generated FCTs certainly hold priority over foreign ones. Although a regional food composition database will help to complement national ones, it is strongly recommended that each country should establish its own food composition database in line with the local situation and needs.

Food composition data system involves data generators, compilers and data users; hence collaboration among them is essential. Each of these key persons plays an important role in the entire process. Data users could contribute some input regarding their requirements for prioritising food items and nutrients to be analysed further. These could also be used as a guideline to develop a user handbook and plan for future revision and improvement of the existing food composition data. With some effective guidelines, data generators should be able to develop food composition data with clear and unambiguous information. Compilers should prepare themselves with background knowledge on data generation and uses, to increase their effectiveness in data scrutiny and assessment. Moreover, some understanding of the development of food composition data could also help users to optimise use of the database.

Development of national and regional food composition databases is very tedious work. Without collaboration and understanding among the data generators, users and compilers at both levels, as well as support from international organisations (i.e. UNU/INFOODS, JICA, FAO) and other regional networks (namely Food Composition Data Centre of OCEANIA countries (OCEANIA FOODS) and Asia Pacific Food Analysis Network (APFAN)), this task would never be achieved.
Gratitude is sincerely expressed for support from all these groups.

\section{Acknowledgements}

The author would like to acknowledge Dr Anadi Nitithamyong and Mr Brent Bateman for their kind editing of this paper.

\section{References}

1 Nutrition Research and Development Center. Daftar Komposisi Bahan Makanan. Indonesia: Nutrition Research and Development Center, 1995.

2 Siong TE, Noor MI, Azudin MN, Idris K. Nutrient Composition of Malaysian Foods, 4th ed. Malaysian Food Composition Database Programme. Kuala Lumpur: Institute of Medical Research, 1997.

3 Portugal TR, Apilado RJ, Ardena JG, Avena EM, Matibag PM, Reyes GD, et al. The Philippines Food Composition Tables 1997. Metro Manila: Food and Nutrition Research Institute, Department of Science and Technology, 1997.

4 Food and Nutrition Department, Ministry of Health. The Composition of Foods Commonly Eaten in Singapore. Singapore: Food and Nutrition Department, Ministry of Health, 1998.

5 Puwastien P, Raroengwichit M, Sungpuag P, Judprasong K. Thai Food Composition Tables. Bangkok: Institute of Nutrition, Mahidol University, 1999.

6 National Institute of Nutrition. Nutritive Composition Tables of Vietnamese Foods [in English and Vietnamese]. Hanoi: National Institute of Nutrition, 2000.

7 Greenfield H, Southgate DAT. Food Composition Data: Production, Management and Use. London: Elsevier Science, 1992

8 Rand WM, Pennington JAT, Murphy SP, Klensin JC. Compiling Data for Food Composition Data Bases. Tokyo: United Nations University, 1991.

9 Coordinating Office of ASEANFOODS. Creation of the First ASEANFOODS Food Composition Database. Report of the ASEANFOODS Workshop, 10-15 March 1996. Bangkok: Institute of Nutrition, Mahidol University, 1996.

10 Nutrition Division, Department of Health, Ministry of Public Health. Nutritive Values of Thai Foods, 2nd ed. Bangkok, Thailand, 1992.

11 Fisheries Division, Ministry of Agriculture and Cooperatives. Fish and Aquatic Animals in Thailand: With Illustration, 2nd ed. Bangkok: Kurusapa Printing Office, 1993.

12 Surin M, Somsuk M. Encyclopedia of Plants and Animals Vols. 1, 2, 3 and 4 [in Thai]. Bangkok: Praae Pittaya Publishers, 1990.

13 Kasetsart University. Agricultural Information (1999) [online]. Available at http://www.ku.ac.th/AgrInfo/. Accessed 1999

14 Dowell P, Bailey A, Lambert Ortiz E, Radecka H. The Book of Ingredients, 8th ed. England: Penguin Books Ltd, 1995.

15 Pijpers D, Constant JG, Jansen K. The Complete Book of Fruit: An Illustrated Guide to over 400 Spices and Varieties of Fruit from all over the World. New York: Gallery Books, 1996.

16 Ministry of Agriculture and Cooperatives, Fisheries Department, Thailand. Aquatic Fauna of Thailand (poster).

17 Ministry of Agriculture and Cooperatives, Fisheries Department, Thailand. Freshwater Fishes of Thailand (poster).

18 Ministry of Agriculture and Cooperatives, Fisheries Department, Thailand. Marine Fishes of Thailand (poster). 
19 Phithakpol B, Varanyanond W, Reungmaneepaitoon S, Wood H. The Traditional Fermented Foods of Thailand. Kuala Lumpur: ASEAN Food Handling Bureau, 1995.

20 US Department of Agriculture, National Plant Data Center. The PLANTS Database 1997 [online]. Available at http:// www.plants.usda.gov.

21 Klensin JC, Feskanich D, Lin V, Truswell AS, Southgate DAT. Identification of Food Components for INFOODS Data Interchange. Tokyo: United Nations University, 1999.

22 Burlingame BA. INFOODS TAGNAMES: update. Prepared for ASEANFOODS Food Composition Workshop, March 1996. Palmerston North: New Zealand Institute for Crop and Food Research, 1996

23 National Association of Testing Authorities (NATA). New Statistics for NATA's Proficiency Testing Programs. Australia: NATA, 1996.
24 ISO 3166: International Standard Codes for the Representation of Names of Countries [online]. Available at http://www.iso.ch/iso/en/prods-services/iso3166ma/02iso3166-code-lists/list-en1.html.

25 FAO/VDD. Fruits of Vietnam (poster).

26 FAO/VDD. Vegetables of Vietnam (poster).

27 Puwastien P, Burlingame B, Raroengwichit M, Sungpuag P. ASEAN Food Composition Tables. Bangkok: Institute of Nutrition, Mahidol University, ASEANFOODS Regional Centre and INFOODS Regional Database Centre, 2000.

28 Schubert A, Holden JM, Wolf WR. Selenium content of a core group of foods based on a critical evaluation of published analytical data. J. Am. Diet. Assoc. 1987; 87: 285-99.

29 Schakel SF, Buzzard LM, Gebhardt SE. Procedures for estimating nutrient values for food composition databases. J. Food Comp. Anal. 1997; 10: 102-14. 